looked at from above, and an observer may be likely to look up in many cases when the 'devil 'is not well defined at the ground.

An analysis of reports in which the sense of rotation is given with the observer looking down on the whirl, shows that 27 out of a total of 29 are reported as anticlockwise (or cyclonic). Most of these observations came from one station, and observations are required from other stations before the apparently anomalous behaviour of 'dust devils' can be explained.

Meteorological Office, Heliopolis, J. DURWard. July 23.

\section{Constitution of Anthocyanins.}

As the result of synthetical work in Great Britain, combined with analytical observations by Karrer and his collaborators in Zurich, the position of the sugar groups in the main anthocyanins of the pelargonidin, cyanidin, and malvidin series can be fixed with a tolerably close approach to certainty.

We suggest that pelargonin, peonin, cyanin, and malvin are not biosides at all, but are di-monosides with separate glucose residues attached to positions 3 and 5 in the anthocyanidin nucleus. Mecocyanin, prunicyanin, keracyanin, and others of similar type, are, however, biosides; the biose group being in position 3. The arguments are a little too involved to put forward here in detail, but we wish to point out that the new idea of the constitution has an important consequence.

The anthocyanins are now considered to be related as follows :

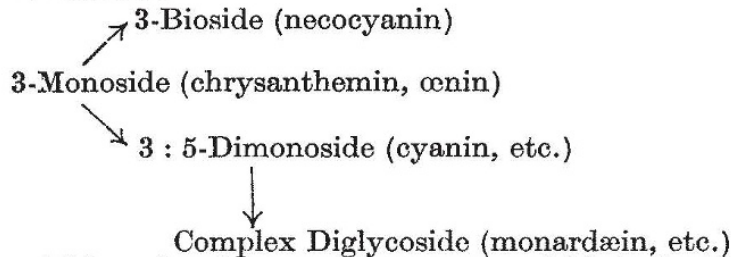

This rather destroys the contrast which is the basis of Miss Scott Moncrieff's interesting letter in NaturE of June 27, because the two types of anthocyanin are to be regarded as brethren rather than as cousins. Nevertheless, Miss Scott Moncrieff's rule holds in the majority of cases.

We have recently examined a large number of related varieties of garden flowers, and find that the two sugar types occasionally occur in varieties of a single species; thus both types of pelargonidin diglycoside and both types of cyanidin diglycoside are found in different sweet-peas.

G. M. RoBINSON

Dyson Perrins Laboratory, Oxford, Aug. 18.

\section{Reaction between Hydrogen Sulphide and Sulphur Dioxide.}

Ir is known that there is no reaction between hydrogen sulphide and sulphur dioxide in the dry state, and that mercury, benzene, or carbon tetrachloride have no effect on a mixture of the dry gases.

In the course of an investigation on the reaction between hydrogen sulphide and sulphur dioxide in non-aqueous solutions, we have found that the two gases when dissolved in benzene or carbon tetrachloride do react in the presence of mercury even when suitable precautions are taken to exclude moisture and oxygen from the reaction vessel. But a solution of hydrogen sulphide or of sulphur dioxide in either of the organic solvents has no action on the metal.
We have reason to believe that thiosulphonic acid is the primary product of the reaction between the gases:

$$
\mathrm{SO}_{2}+\mathrm{H}_{2} \mathrm{~S} \rightleftharpoons \mathrm{O}_{\mathrm{H}}^{\mathrm{O}} \overbrace{\mathrm{SH}}^{\mathrm{SH}}
$$

and that at the interface between the organic solvent and mercury the thiosulphonic acid is decomposed, producing sulphoxylic acid and the metallic sulphide. Displacement of the equilibrium in the above equation is caused by the formation of the sulphide, which lowers the interfacial tension between mercury and the organic liquid.

Further work is in progress.

Baskur Sanjtva Rao.

M. R. Aswathnarayana Rao.

Central College (Mysore University), Bangalore, S. India, July 16.

\section{A Method of Studying Surface Films.}

If a substance, for example, ergosterol, is spread in a mono-molecular layer on the surface of water contained in the tray of a Langmuir-Adam apparatus for the measurement of surface films, it is possible to make the following observations.

Where a continuous mono-molecular film is formed, one is able to see that waves, produced at the surface by a tuning-fork, show a very strong diminution of their amplitude. The experiment is very easily performed: waves are produced by an electrically-driven tuning-fork, which is in contact with the surface of the water in the tray by a dipple: the wave-length of these waves can be about $0 \cdot 4$ centimetre. A beam of parallel rays is thrown vertically on the surface, where it is reflected. The reflected light is concentrated by a lens ( 5 dioptr.) in a single point on a scale. As soon as waves disturb the surface, the point is distorted into a straight line. Now, the influence of the spreading substances is to diminish tho amplitude of the waves, and this is determined by a shortening of the line of reflected light.

We have studied different substances, and have observed that not every spreading substance shows the phenomenon in the same very striking way. Nevertheless, we believe that this method of studying surface films has some advantages. It is possible to make measurements at zero pressure, and the method gives results that are very well reproducible.

Proteins also show the phenomenon.

We hope that exact quantitative measurements of the effect will onable new capillarity constants to be determined.

E. Gorter.

Leyden.

W. A. SEHDER.

\section{Insectivorous Snakes.}

In the letter of Messrs. Miller and Pagden in Nature of May 9 it is stated that " records of insects having been devoured by snakes do not appear to be abundant". During some work on the parasites of snakes at Thandaung fiftoen Simotes violaceus were dissected. In all cases the stomach and intestine were full of insect remains, sometimes very tightly packed and completely filling the lumen, chiefly those of a small brown grasshopper. In only one case were any vertebrate structures found: a small newt and a viper's tooth. Remains of insects were also found in Natrix piscator, N. chrysargus, and Trimeresurus gramineus.

Biological Department,

F. J. Megariti.

University of Rangoon. 